\title{
Representaciones Acerca Del Desarrollo En Tierra Del Fuego
}

Mariano HeRmida

Resumo: O artigo se origina no contexto de uma pesquisa sobre o sistema de informação para monitorar o desenvolvimento sustentável na Terra do Fogo. A revisão da literatura acerca do desenvolvimento, tema sempre presente no discurso político, serve de base para examinar as representações que os atores estatais fazem desse conceito e sua associação com a ideia de sustentabilidade, bem como da utilidade da estatística para o desenho de políticas públicas.

\section{Palavras-chave:}

Sustentabilidade;

Políticas públicas; Desenvolvimento; Informação estatística; Terra do Fogo.

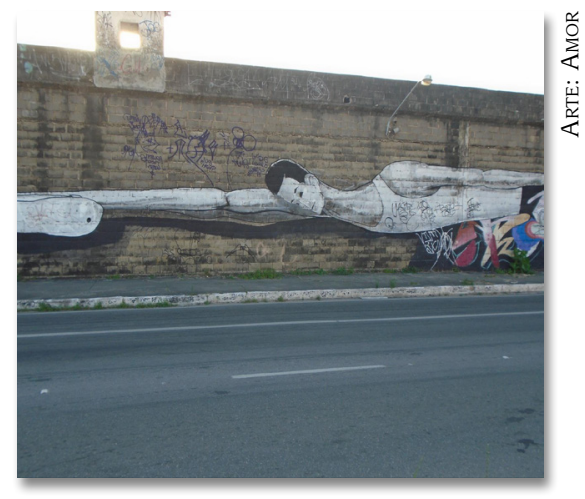

\section{Representations on Tierra del Fuego development}

\section{Mariano Hermida}

Sociólogo pela Universidade de Buenos Aires e doutorando em Política e Economia na Universidade Ncional de San Martin. Pesquisador e profesor na Universidade Nacional de Tierra del Fuego. mhermida@untdf.edu.ar
Abstract: The article originates in research on the information system for monitoring sustainable development in Tierra del Fuego. It examines the representations of state officials concerning the concept of development and its association with the idea of sustainability as well as their ideas on the utility of statistics for the design of public policies. This analysis is based on a literature review of development, an issue always present in political speech.

Keywords:

Development: Sustainability; Public Policy, Statistical information; Tierra del Fuego.

RECEBIDO EM $29-05-2014$

Aprovado EM: $06-04-2015$ 


\section{INTRODUCCIÓN ${ }^{1}$}

Solemos suponer que para caracterizar, definir y monitorear el grado de desarrollo de un territorio es necesario contar con información sistematizada. Esa misma información es la que respalda el diseño y evaluación de las políticas públicas que garantizan ese desarrollo. Estos supuestos están implícitos en la tesis de Maestría en Generación y Análisis de Información Estadística de la Universidad Nacional de Tres de Febrero": "Hacia un sistema de información estadística para el monitoreo del desarrollo local sostenible en la Provincia de Tierra del Fuego, Argentina".

Hacia mediados de 2013 la Universidad Nacional de Tierra del Fuego, involucrada en el desarrollo del proyecto de investigación, "Dinámicas institucionales y procesos de construcción territorial", nos brindó la posibilidad de indagar acerca del marco de necesidad de un sistema de información que monitoree el desarrollo sostenible en Tierra del Fuego.

En términos puntuales, ¿qué entienden los funcionarios políticos estatales por desarrollo? ¿a qué asocian la idea de sostenibilidad? Y finalmente, ¿utilizan información estadística para el diseño de políticas públicas?

Para responder a estas preguntas hemos realizado siete entrevistas en profundidad, durante los meses de octubre y noviembre de 2013, a funcionarios políticos de la provincia de Tierra del Fuego. Los mismos han sido seleccionados teniendo en cuenta cierta heterogeneidad: distintos niveles de gobierno, municipales y provinciales; diversos poderes, legislativos y ejecutivos; y disímiles facciones políticas.

En algún sentido, el presente documento intentará observar si los supuestos que acompañan el diseño de un sistema de

1 Una versión preliminar del presente documento fue presentado en el Congreso Pre ALAS VI foro Sur-Sur, que desarrolló la Universidad Nacional de la Patagonia Austral en la ciudad El Calafate, provincia de Santa Cruz, Argentina, del 7 al 9 de mayo de 2014 .

2 Debemos mencionar que el desarrollo de la tesis se encuentra asociado al Proyecto de Investigación Científica y Tecnológica ((PICTO-UNTREF 2010-0104) "Sistema de Información Estadístico para el Desarrollo Sustentable de Áreas Locales (SIEDSAL)", amabas en la misma unidad académica, la Universidad Nacional de Tres de Febrero. 
información estadístico para el monitoreo del desarrollo local sostenible son utilizados en la actualidad, o si se deberá generar un espacio de necesidad futura para que la elaboración y evaluación de las políticas públicas, que sean garantes del desarrollo, se basen en indicadores.

\section{DEL CRECIMIENTO AL DESARROLLO SOSTENIBLE ${ }^{3}$}

El término desarrollo no estuvo presente en la literatura desde siempre, en realidad su origen se puede remontar hacia finales del siglo XIX y principios del XX. En el marco de las fuertes trasformaciones poblacionales producto de la segunda transición demográfica y la segunda revolución industrial, el mundo se ve alterado.

Donde se implantaba una fábrica el territorio cambiaba, la velocidad con la que circulan las personas, las relaciones entre ellas y el hábitat que lo circundaba se transformaba. Por supuesto el modo en que se analizaban esas interacciones cambió, el crecimiento teórico de las ciencias sociales durante dicho período se basa en los altos procesos de transformación, con diferentes posiciones pero todas basadas en el cambio. Es en este contexto que aparece la idea de "desarrollo", ahora bien ¿en qué sentido? (QUETGLAS, 2008, p. 15-34).

a) Como resultado social. Se leía al desarrollo como una transformación social positiva, es decir no se veía en él nada negativo, al contrario, este proceso es entendido como sinónimo de progreso, como tal incluye la idea de que la urbanización es deseable y se debe intensificar.

\footnotetext{
3 Parece existir en la bibliografía cierto debate acerca de las diferencias que podría implicar lo sostenible y lo sustentable, y sus conceptos próximos tales como sostenibilidad y sustentabilidad. Sin embargo estos preciosismos terminológicos son lo suficientemente discutibles (GALLOPÍN, 2006). Reboratti (2000) afirma que no existe una diferencia conceptual entre ellos, sino un proceso que viene asociado a una conversión "algo mágica" en el terreno de las traducciones, es probable que cierto fanatismo por los anglicismos fuera en detrimento del término existente en español que es sostenible. En este aspecto coincidimos con Gallopín y Reboratti quienes afirman no existir diferencias entre uno y otro término, y la gran difusión de ambos parece corroborar la misma línea. En este sentido hemos decidido utilizar sostenible ponderando al mismo por sobre sustentable, dado que el primero se corresponde con nuestro idioma.
} 
b) La segunda acepción es la que asocia al desarrollo como industrialización, se lo lee como sinónimo de la modernización y sigue conteniendo un fuerte sentido positivo. El crecimiento del sector secundario requería una importante intervención en los procesos de alfabetización, por este motivo el concepto se empieza a relacionar a las políticas educativas.

c) La tercera acepción del término es mucho más valorativa, e identifica al desarrollo con un proceso superador de las etapas "anteriores" del modelo de producción y con ello las anteriores formas de sociedad, es desde esta perspectiva que se asocia desarrollo a "sociedad moderna", siendo su contra cara la "sociedad tradicional", en algún sentido la vieja dicotomía "comunidad-sociedad" (CARDOSO; FALETTO 1999, p. 11-13).

Ahora bien la visión neoclásica del desarrollo económico "se apoya sobre la base de unos factores productivos dados y el doble supuesto de perfecta movilidad de factores, por una parte, y de total flexibilidad de la variable precio por otra, para afirmar que más tarde o más temprano se llegara al equilibrio de la renta y de la producción y, en consecuencia, al pleno empleo en el uso de los recursos". (AGUADO; ETXEBARRIA; BARRUTIA, 2009, p. 92). En este sentido el desarrollo no tiene límites, al menos en los términos de los recursos naturales, desde esta óptica el desarrollo se observa como sinónimo de progreso ilimitado. Tal como se aprecia en los párrafos anteriores, si bien existían posiciones críticas, la asociación conceptual entre desarrollo y crecimiento, principalmente industrial, va estar presente en el análisis de las ciencias sociales, especialmente dentro de la economía ${ }^{4}$, desde finales de siglo XIX hasta principios del XX.

Tal como señala Aguado, Etxebarria y Barrutia (2009, p. 94, 100) "tras la Segunda Guerra Mundial empezaron a surgir algunos

4 De más está decir que desde nuestra visión la economía es una ciencia social, al igual que la sociología o la ciencia política, cuestión por la cual cuando nos referimos a los científicos sociales estamos agrupando tanto a los economistas como a los sociólogos. 
trabajos empíricos que pretendían analizar las diferencias encontradas entre los diversos procesos de crecimiento desarrollados en el mundo, alzándose de esta manera, las primeras voces discordantes con la ortodoxia económica dominante, herederas fundamentalmente de los postulados keynesianos". Es durante este período que surgen dos novedades conceptuales: "a) el desarrollo adquiere estatus de categoría política significativa porque ingresa a los documentos oficiales b) por primera vez el desarrollo se articula con la democracia política, en una relación de fuerte correspondencia" (QUETGLAS, 2008, p. 22-23).

Hacia mediados de siglo XX el desarrollo se asocia intrínsecamente a lo que conocemos como sociedad industrial. Así es como en menos de un siglo el concepto pasa a formar parte de la agenda oficial y a estar siempre presente en el debate político. En este sentido podemos definir cinco corrientes del pensamiento económico-social que han contribuido durante el período analizado al concepto de desarrollo: la Teoría de la Modernización, la Teoría Estructuralista, la Teoría Neomarxista, la Teoría Neoliberal y las Teorías Alternativas (AGUADO; ETXEBARRIA; BARRUTIA, 2009, p. 94, 100).

Parte de la posición crítica a las diferencias entre países fue gestionada desde la CEPAL, quien con "intelectuales como Raúl Prebisch o Celso Furtado, entre tantos otros, realizaron valiosas contribuciones acerca del carácter estructural del subdesarrollo latinoamericano, así como apuntaron a diseñar estrategias de desarrollo "hacia adentro". Sin embargo, el paradigma del desarrollo postulado en los años 50 por la CEPAL, e ilustrado por las experiencias nacionaldesarrollistas entre los años 50 y 70, que colocaban al Estado como un actor central (en términos de productor y regulador de las relaciones sociales), fue ampliamente criticado, desde diferentes vertientes y posicionamientos político-ideológicos: desde el marxismo, tanto la corriente de la dependencia como los teóricos de la marginalidad, no sólo cuestionaron el carácter reformista de dichos modelos sino los límites de su capacidad de integración, al tiempo que señalaban como horizonte o como "concepto límite" la alternativa revolucionaria. Así, por encima de las diferencias político-ideológicas, se tratase de la perspectiva desarrollista o de la izquierda revolucionaria, al volver sobre aquellos tiempos es posible rescatar la disposición a pensar 
modelos de desarrollo, concebidos en términos de proyectos alternativos de sociedad" (SVAMPA, 2008, p. 1-2).

En la década de los setenta el debate del crecimiento económico cambia de rumbo. Se comienza a cuestionar los límites del mismo por lo que se comienza a observar la necesidad de considerar "límites biológicos del planeta, en un contexto en el que los efectos perniciosos que la crisis económica estaba ocasionando sobre el medio ambiente y sobre la calidad de vida eran cada vez más palpables" (AGUADO; ETXEBARRIA; BARRUTIA 2009, p. 99-100).

Por un lado estaban los catastrofistas para quienes la continuación del ritmo de crecimiento llevaría, en el correr del siglo XXI, a una catástrofe ecológica y humana, debido principalmente a la escasez de recursos naturales. Dentro de esta línea, el informe para el Club de Roma Los límites del crecimiento (1972) constituyó un mojón en la discusión. Por otro lado, estaban los tecnócratas optimistas, los cornucopianos, que defendían la inagotable fuente de la naturaleza y el eficaz mecanismo del mercado como regulador del uso de los recursos; véase, por ejemplo The Resourceful Earth (1984). Para estos no se vislumbra crisis ambiental alguna. También estaban los ecologistas a ultranza, que frente a la crisis de la sociedad industrial abogaban por una "vuelta al pasado" en una reivindicación romántica de la vida rural en pequeñas comunidades autosustentables. Para deslindarse de estas posiciones surgieron una serie de planteos tendientes a interpretar la crisis ambiental y ofrecer una salida "viable" al capitalismo. El término "ecodesarrollo" y luego el de "desarrollo sustentable" constituyen el centro de la discusión (FOLADORI; TOMMASINO 2000, p. 43-44).

Este devenir en las agendas oficiales continúa en 1983 con el establecimiento de una comisión especial de la ONU que debería elaborar un informe sobre el medio ambiente y la problemática mundial hasta el año 2000 y más adelante. De esta forma en 1987 la Comisión Mundial sobre el Medio Ambiente y el Desarrollo (CMMAD) presentarán su famoso informe "Nuestro Futuro Común", también conocido como "Informe Brundtland", en el que se exponen los cuatro años de estudio.

En este contexto surgen algunas divergencias principalmente encaradas por un grupo de teóricos de la Fundación Bariloche, que construyeron el Modelo Mundial Latinoamericano, en donde se 
aceptaba la existencia de límites físicos, pero demostraba que en realidad los límites operacionales de la humanidad eran sociopolíticos y no físicos, lo que se traduce en que puedan ser ampliables dependiendo de la voluntad del ser humano. A su vez proponían y describían una sociedad equitativa e intrínsecamente compatible con el medio ambiente (GALLOPÍN, 2006, p. 4).

El Modelo Mundial Latinoamericano propone una sociedad igualitaria, no consumista y donde la producción esté determinada por las necesidades sociales y no por la ganancia, y principalmente con un cambio en el concepto corriente de propiedad que debe ser remplazado por el más universal uso de los bienes de producción y la tierra.

Hacia 1990 el Programa de las Naciones Unidas para el Desarrollo (PNUD) elabora el primer informe sobre el Desarrollo Humano, confeccionado por Amartya Sen "junto con un grupo destacado de economistas entre los que se encontraban Mahbub Ul-Haq, Paul Streeten, Meghnad Desai, Gustav Ranis y Keith Griffin" (PICAZZO PALENCIA et al., 2011, p. 258). Este informe es el proceso final de un debate iniciado en los setenta y sostenido por casi dos décadas por académicos como Streeten y el mismo Sen (AGUADO; BARRUTIA; ECHEBARRIA, 2008, p. 4). Desde la esta perspectiva el desarrollo es definido como un proceso de expansión de las libertades reales de las que disfrutan los individuos. De esta forma elabora una metodología que permita medir al desarrollo desde esta configuración, por lo que el desarrollo debería medirse siguiendo el aumento de las libertades de los individuos, De esta forma aparecen en el debate conceptos como justicia y equidad.

Este enfoque superó la visión economicista centrada en el tener y propuso una visión multidimensional, que intenta ser holística, centrada en el ser y el hacer del ser humano, es decir en su bienestar y en sus capacidades, desde la cual la participación de las instituciones juega un papel preponderante. En este sentido se considera al desarrollo como un proceso de expansión de las libertades reales de las que disfrutan los individuos (PICAZZO PALENCIA et al., 2011, p. 259).

Es el mismo Sen (1998) el que define dos tipos de libertades: las que son constitutivas, que permiten al ser humano alcanzar una 
vida plena con calidad (es decir sin las privaciones básicas que limitan la vida, la adquisición de las capacidades sociales y culturales básicas); y las libertades instrumentales, definidas como aquellas oportunidades y derechos que contribuyen directa o indirectamente a la libertad general de las personas (los servicios económicos, las instituciones, las oportunidades sociales como los servicios de salud, la protección social y jurídica) (PICAZZO PALENCIA et al., 2011).

Desde estos aportes se aparta conceptualmente la estrecha relación que existía entre el desarrollo y el crecimiento económi$\mathrm{CO}$, traducido en el Producto Bruto Interno (PIB), también se corre de los tradicionales análisis basados en el aumento de los ingresos, la industrialización y el progreso tecnológico. Al entender las libertades humanas como oportunidades determinadas por otras realidades como son la salud, la mejora en las condiciones de vida y un aporte importante del ejercicio de las libertades democráticas (SEN, 1998), dando lugar a los derechos cívicos y sociales, lo que se traduce en las posibilidades de ejercer presión sobre una política pública adecuada (PICAZZO PALENCIA et al., 2011, p. 261).

De esta forma las críticas al desarrollo entendido simplemente como sinónimo de crecimiento basadas en una ampliación de sus aspectos sociales, principalmente en la accesibilidad de derechos tales como la salud y la educación, sumada a la crítica en aspectos ambientales comienza a entrañar una nueva concepción del desarrollo, no sólo en términos humanos, sino incluyendo a la sustentabilidad del medio ambiente como parte intrínseca de su conceptualización.

Desde la perspectiva histórica observamos como el concepto de desarrollo fue ampliando sus fronteras desde el crecimiento plenamente industrial, a la observación de otros sectores productivos, y especialmente la ampliación hacia los derechos sociales y la discusión acerca del ambiente, distinguiendo los límites de dicho crecimiento. Este proceso por el que ha transitado el concepto nos lleva a discutir acerca del desarrollo sostenible. Desde su aparición en el famoso Informe Bruntland ("Nuestro futuro común") redactado por las Naciones Unidas en 1987, su difusión y aceptación ha sido extremadamente amplia. 
En términos del informe "está en manos de la humanidad hacer que el desarrollo sea sostenible, duradero, o sea, asegurar que satisfaga las necesidades del presente sin comprometer la capacidad de las futuras generaciones para satisfacer las propias. El concepto de desarrollo duradero implica límites, no límites absolutos, sino limitaciones que imponen a los recursos del medio ambiente el estado actual de la tecnología y de la organización social la capacidad de la biósfera de absorber los efectos de las actividades humanas. Pero tanto la tecnología como la organización social pueden ser ordenadas y mejoradas de manera que abran el camino a una nueva era de crecimiento económico". (NACIONES UNIDAS, 1987, p. 23).

En este sentido el desarrollo sostenible es un concepto amplio, hasta ambiguo, que se asocia a la idea de progreso pero que se encuentra circunscripto a la finitud de los recursos naturales. También es global ya que supone una mirada que contemple la diversidad, tanto social, económica, ambiental, como la local, nacional o regional. En este sentido diferenciamos al desarrollo del manejo sostenible, este último puede estar basado en las pautas de baja degradación del ambiente, pero no contemplar derechos sociales.

Esto significa que no es que la sociedad realiza el desarrollo sostenible del ambiente, sino que el desarrollo sostenible de la sociedad incluye, entre otras, una dimensión ambiental (REBORATTI, 2000, p. 199-200).

A esta altura está claro que desarrollo no es sinónimo de crecimiento, el primero puede contener al segundo, pero el segundo no necesariamente al primero. Por ejemplo, crecimiento del Producto Bruto Interno no significa distribución de la riqueza, ni tampoco reducción de la pobreza, que sí deben ser contenidos necesariamente por el desarrollo. De esta forma, el desarrollo sostenible no puede contener desigualdad social, en el mismo sentido un ecologismo vacío, simplemente garantista de los recursos naturales, que mantenga las asimetrías, sostenga la pobreza e invisibilise la vulnerabilidad social, carece de sentido (SVAMPA, 2009). En síntesis se trata de un concepto compuesto por el crecimiento económico, la observación del ambiente, y la equidad social, todos ellos en un marco de fuerte democracia (AROCENA, 2009, p. 17). De más está decir que en este espacio no nos proponemos fijar 
las metas del desarrollo sostenible sino establecer las dimensiones que se contienen (GALLOPÍN, 2003).

En este contexto, la definición de indicadores de sostenibilidad bajo una cuádruple dimensión (económica, social, ambiental e institucional) que equilibre los aspectos sociales, económicos, ambientales e institucionales, a través del denominado Prisma de Sostenibilidad [...] puede contribuir tanto a facilitar una adecuada comunicación de los principios de sostenibilidad como a la medición de los progresos realizados (AGUADO; BARRUTIA; ECHEBARRIA, 2008, p. 14).

Por ende nos encontramos con las cuatro dimensiones comúnmente aceptadas que conforman el denominado Prisma de Sostenibilidad: lo social, lo económico, lo institucional y lo ambiental. Desde una perspectiva sistémica cada una de estas dimensiones implica un subsistema que tienen funciones o relaciones entre ellos.

Esquema 1. Sistema de desarrollo sostenible

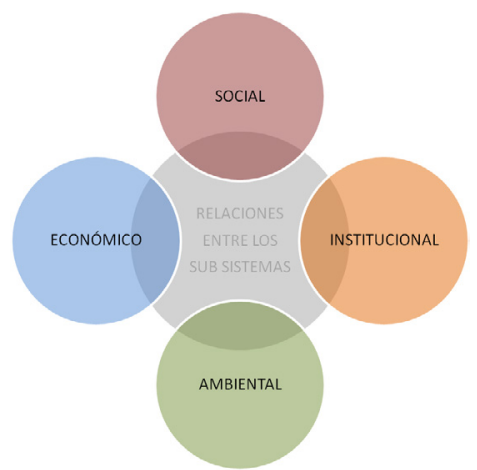

Fuente: Elaboración propia en base a Gallopín (2003).

Este modelo multidimensional expresado en el Esquema 1 permite aproximar la riqueza que el concepto de desarrollo debería contener. Por este motivo si se enfatiza sólo en una de las dimensiones, sea este el crecimiento económico, o la equidad social, o simplemente se cuida el ambiente, o se resguarda las instituciones, alguno de las partes se va a ver desbalanceada y el desarrollo no será completo. 


\section{LAS REPRESENTACIONES LOCALES DEL DESARROLLO}

Tal como se observó en el capítulo anterior, podríamos resumir los conceptos en cuatro grandes postulados. Aquel que refiere al crecimiento económico, el que se asocia al desarrollo como sinónimo de industrialización, y dos concepciones multidimensionales, aunque distintas entre sí, que son la de desarrollo humano y la de desarrollo sostenible. En este sentido, ¿Qué entienden los funcionarios políticos por desarrollo? ¿Lo observan sostenible? Y con mayor precisión, ¿a qué asocian la idea de sostenibilidad del desarrollo?

Un primer análisis de las respuestas nos permite establecer ciertas divergencias. Por un lado está quien identifica el desarrollo con el crecimiento económico, similar a una concepción liberal del mismo, evidenciando la falta de relación entre distintas dimensiones:

[...] por desarrollo entiendo [...] el crecimiento, el avance, el enriquecimiento que puede tener una sociedad en general y que llega a todas las personas. El desarrollo tiene que ver con la posibilidad de crecer, de ir avanzando. Obviamente, como en un efecto de dominó, va primero llegando a las empresas, va llegando a los comercios, y esto se va desparramando en la gente. [...] (funcionario del ejecutivo municipal)

Luego se identifica a un grupo que asocia desarrollo al desarrollo humano, por ende el concepto adquiere relevancia en la mejora de las condiciones y la calidad de vida de los sujetos. Muchos de ellos le confieren una característica local a la conceptualización. Este sentido se puede asociar al de desarrollo endógeno, es decir propio o "genuino" en contraposición al desarrollo implantado o generado "desde afuera":

Pero el desarrollo para mí no es que le vaya bien a este tipo, es que nos vaya bien a todos. (funcionario del ejecutivo provincial)

El desarrollo son medidas permanentes y sistemáticas que están concatenadas, articuladas unas con otras, en vistas de distintos objetivos o de metas, que tienen que ver no sólo con el crecimiento sino también con el mejoramiento de la calidad de vida. Atraviesa todo. (ex funcionaria del ejecutivo provincial) 
El desarrollo en Tierra del Fuego es tener la posibilidad de una ciudad organizada con plena ocupación y que no haya sectores marginados. Es lo que uno pretende. Tener una comunidad donde todos puedan desarrollarse. Y cada uno con el tiempo ir mejorando su estándar de vida. (funcionario del legislativo municipal)

El desarrollo es crecimiento genuino. No es la electrónica, por ejemplo. Sí los bosques, sí el mar. Sí lo que es genuino, lo que es de acá. No lo que se puede levantar un día e irse. [...] Está protegido por una ley, mañana la ley se levanta -o ante alguna crisis- y las fábricas se levantan y se van. Lo otro no se puede ir: pesca, madera, lana, investigar sobre nuevas formas de cultivos para lugares como estos, llevar adelante una experiencia de desarrollo en ese sentido. [...] Eso crea fuente de trabajos y crea verdaderas raíces. (ex funcionario del ejecutivo provincial)

El desarrollo solamente aparece asociado a lo ambiental en una sólo oportunidad, su exclusión en la mayoría de los relatos invita a preguntarnos ¿Tierra del Fuego no debería pensar en un desarrollo multidimensional que incorpore la dimensión ambiental?

Para mi le desarrollo es el crecimiento integral de una sociedad, de una provincia, pero siempre pensando en las generaciones futuras. Que el desarrollo sirva para lograr una sustentabilidad económica, ambiental, etc. Es ir satisfaciendo las necesidades de la población, las expectativas de trascendencia de la población, las oportunidades de la población dejando esas mismas oportunidades para la gente que viene. (funcionario del legislativo municipal)

En síntesis, encontramos un discurso asociado principalmente al desarrollo humano, y en algunos casos local o endógeno. Esto implica una ampliación de las fronteras del antiguo concepto subsumido al crecimiento económico, aunque hemos encontrado algunos resabios de dicho concepto en ciertas definiciones. La singularidad de la dimensión ambiental en único caso refuerza la concepción de un desarrollo en el que prima las dimensiones económica y social, dejando de lado las dimensiones ambiental e institucional. Sobre esta última vale la pena realizar un comentario, ninguno de los entrevistados observa la necesidad de que el desarrollo se genere en el marco de una fuerte democracia, ni tampoco hay mención al respecto de las reglas o pautas institucionales. La 
omisión puede estar basada en la existencia e intensidad de los lazos informales (ACUÑA, 2013).

En cuanto a la sostenibilidad del desarrollo, los entrevistados la asocian a la ley 19.640, en este sentido pierde su característica basada en una configuración multidimensional donde lo sostenible se haya en un equilibrio entre lo social, lo económico, lo ambiental y lo institucional. En síntesis, el futuro no parece estar restringido a los límites físicos, sino a un acompañamiento normativo, que parece haber sido el impulsor del desarrollo presente. Esta asociación nos llevó a indagar acerca del impacto de la ley de promoción industrial en el desarrollo de la provincia.

\section{LA LEY DE PROMOCIÓN INDUSTRIAL ¿CRECIMIENTO O DESARROLLO?}

Luego de distintos intentos por parte del Estado Nacional ${ }^{5}$ por concretar el poblamiento de Tierra del Fuego, en 1972 se promulga la Ley 19.640. Esta reglamentación se concibe con la idea de promocionar la industria, en este sentido brinda algunos beneficios impositivos, tales como la exención del impuesto a las ganancias o el valor agregado (MASTROCELLO, 2007, p. 95-97).

5 Desde finales del siglo XIX hasta principios del XX distintas experiencias apuntan a afianzar el dominio argentino en el territorio, tanto las explotaciones productivas hacia el norte de la provincia, como la consolidación del sistema carcelario en el sur tienen la misma intencionalidad, incentivar el crecimiento poblacional. Basado en la concepción de territorio fronterizo los distintos gobiernos nacionales desarrollaron una geopolítica que permitiese poblar este último espacio de la Patagonia (LUIZ; SCHILLAT, 1997).

Hacia 1947 se incentiva el poblamiento a través de la implementación de bases militares en la isla, cerrando la etapa basada en el traslado forzoso de los internos penitenciarios. Para ello se realizó la intervención en términos de obra pública y el incentivo de la migración internacional a fin de cumplir con el desarrollo urbano.

Sin embargo la tensión limítrofe hacia principios de la década del setenta, es la que da inicio a un crecimiento basado la promoción de la industria, lo que promovió la movilización de miles de argentinos. Para sintetizar, desde 1972 con la promulgación de la ley 19.640 hasta la provincialización en 1990, la población ha crecido de 13.500 en 1970 a 69.369 en 1991. Esta dinámica poblacional se sostuvo durante los últimos veinte años, hecho que se corrobora con el último censo de población, en el que se observan 127.250 habitantes (VAN AERT, 2009). 
La ley funciona otorgando licencias de erogación impositiva a ciertas iniciativas que estén dispuestas a radicarse en el territorio. Esto trajo aparejado un crecimiento paulatino de las actividades relacionadas con la industria electrónica, textil y autopartistas. La atracción de mano de obra impulsó al otro polo del sector secundario, la construcción. La inversión en infraestructura urbana, las viviendas y la instalación de establecimientos productivos se vieron especialmente incentivadas en los años ochenta.

[...] esa fue una ley de poblamiento me parece, ¿no? Geopolítica. Entonces generó una sociedad migrante, atraída por un recurso económico que era un buen sueldo. Y conformó una sociedad con esas características. (funcionario del legislativo municipal)

Dado el criterio original de la ley, el equilibrio entre poblamiento y desarrollo, se debate entre lo nacional, lo local, lo endógeno y lo exógeno. Esta discusión pende a su vez del fino hilo de la siempre presente inestabilidad de la legislación. Así se genera un debate en el que los propios funcionarios presentan un posicionamiento que por momentos se exhibe con tintes contradictorios.

El gobierno generó un crecimiento en base a una promoción pero no fueron cubiertas todas las otras necesidades que trajo el crecimiento poblacional. Creo que en este momento estamos en una situación en la que no podemos darle respuestas a la población que tenemos porque los recursos no alcanzan. Eso no está previsto, como ser una reparación histórica. El mismo Estado nacional tendría que haber sido el que planifique el crecimiento y diga: "el crecimiento de Río Grande, por la instalación de industrias, necesita 2 mil hectáreas para generar todo el desarrollo local que va a tener" (funcionario del legislativo municipal)

El problema tiene que ver con esta cuestión de la dependencia institucional de la gente. Esto se reproduce en aspectos como la ley. Nosotros no tenemos una proyección de qué hacer sin la ley. Nosotros estamos viviendo con la ley hoy y después veremos. No hay planificación al respecto. [...] La ley solamente es por el tema de las fábricas. Se mantiene un equilibrio ahí medio choto. Un día de estos van a sacar la ley y la van a sacar no porque quieran sino porque no queda otra. [...] Yo creo que sin la ley de promoción, la población de la provincia sería menos de la mitad. [...]. La ley de promoción industrial es importantísima para el desarrollo 
provincial. Es muy importante. Ahora, genera deformaciones también. Genera determinadas inequidades. (funcionario del ejecutivo provincial)

Estas "inequidades" o "distorciones" a las que se refiere el funcionario, dejan en otros la sensación de falta de desarrollo:

no, de ningún modo, de ningún modo. Dos cositas que sabemos todos. Varía el precio de la soja y Santa Cruz desarrolla la industria -porque viste que ahora sacaron una zona franca ahí-, nos compite y se van 5 industrias. Explota Tierra del Fuego. Simplemente eso. Explota. No se pueden pagar los sueldos estatales, no hay manera de atajar... somos todo lo contrario de una sociedad sustentable. (funcionario del ejecutivo provincial)

Estamos mirando y pendiente de que no vaya a venir alguien malo que nos saque lo que tenemos porque se cae todo. Todo lo que se construyó con unos cimientos no sé si muy sólidos. (ex funcionario del ejecutivo provincial)

Esta concepción ata la sostenibilidad del desarrollo a la ley, lo que brinda una visión de carencia en perspectivas futuras relacionadas al desarrollo local. En este sentido los funcionarios suelen enfatizar en que la ley ha entorpecido la generación de políticas públicas diseñadas para el desarrollo endógeno. Es decir, los entrevistados observan un "desarrollo" exógeno, sostenido "desde afuera", mantenido por y desde la promoción industrial. Las preguntas que surgen son casi evidentes ¿es posible concretar un desarrollo de dicha naturaleza?

La provincia ha tenido un desarrollo que fue muchas veces asistido por el lugar donde estamos, por el nacimiento. (funcionario del ejecutivo provincial)

Es muy cómodo pensar que la 19.640 es la que genera el desarrollo. Crecemos pero no nos desarrollamos. (ex funcionario del ejecutivo provincial)

Tal como observamos en la primera parte del presente documento, crecimiento es muy distinto a desarrollo, el debate que genera la ley invita a pensar cómo se diseñan las políticas públicas. Si se desea un desarrollo endógeno, tal como expresan los discursos antes expuestos, es necesaria también la independencia 
en el diseño, monitoreo e implementación de política que garantice un desarrollo local.

\section{LA INFORMACIÓN ESTADÍSTICA Y LAS POLÍTICAS PÚBLICAS}

Las políticas públicas no siempre son diseñadas y evaluadas desde y por información estadística. De hecho la asociación de política pública e indicadores no es una realidad continua. Sin embargo consideramos que esta no es una unión caprichosa, existen fundamentos teóricos y metodológicos que argumentan a favor de esta alianza. “¿Porque es deseable la política pública basada en evidencia? Porque fundamenta el uso eficiente y racional de los recursos públicos. Porque fortalece la rendición de cuenta de los tomadores de decisiones enfrente de los ciudadanos. Finalmente porque fortalece la transparencia, lo que es deseable en razón de la equidad y eficiencia. En una democracia los ciudadanos tienen el derecho de saber cómo y por qué se toman las decisiones y como estas afectarán sus vidas" (AGUILERA, 2009).

En síntesis, la información es sustancial para la producción de conocimiento, el monitoreo y el diseño de políticas públicas, a su vez la democratización de la misma permite a la sociedad civil debatir acerca de qué tipo de desarrollo es el que considera conveniente (CAVUOTO, 2009, p. 176).

De más está decir que las políticas públicas no pueden ser elaboradas exclusivamente desde un saber técnico. Si son diseñadas con información estadística pero que no atienden las necesidades políticas de la sociedad civil, no son "más válidas" por demostrar mayor nivel de análisis. El discurso de nuestros entrevistados se encuentra en este sentido:

[...] uno de los elementos con los que hay que trabajar fuertemente es con la participación de la gente. Que esto no sea un grupo selecto de gente iluminada que comanda y te lleva $\mathrm{y}$ te trae. Porque esa gente se equivoca y porque esa gente cumple un ciclo y porque esa gente se agota. Entonces hay que trabajar en esto. (funcionario del ejecutivo municipal) 
Tenés que ir acompañando, sin creerte la luminaria [...]. Me parece que es todo un proceso que hay que darse en Tierra del Fuego. Las políticas públicas tienen que tender hacia lo que uno cree que es lo mejor para el desarrollo sustentable, la construcción de ciudadanía, acompañando el proceso, porque sino... (funcionario del legislativo municipal)

Claramente si las políticas no se corresponden con las necesidades ciudadanas no encontrarán legitimidad en la misma, lo que dará por resultado una política ineficaz. Por otro lado es claro que el "saber experto" no es puramente técnico ni objetivo, con lo cual está imbuido de una intencionalidad política que debe quedar expuesta (CAMOU, 1997). Sin embargo tal como hemos enfatizado en los párrafos anteriores, la información debe ser utilizada y democratizada tanto en la etapa de diseño, monitoreo, y evaluación. En nuestro caso ¿Qué elementos acompañan las políticas públicas?

Primero poder tener la visión de qué gobierno quiero. Después, poder identificar a todos aquellos actores que pueden estar acompañando esta visión. Cuando digo visión, lo digo en términos de desarrollo, para dónde quiero ir. Quiénes son esos actores que están acompañándome y quiénes son los que pueden estar acompañando esto. Esto presupone un diagnóstico previo de situación para ver si lo que yo me estoy planteando va a ser sostenido. (ex funcionaria del ejecutivo provincial)

Primero hay que hacer una caracterización de lo existente. Tenés que tener una evaluación situacional de cómo está hoy la provincia en términos de desarrollo económico. Después, tener una idea de a dónde se quiere avanzar. En esa diferencia entre lo que somos y lo que queremos, ¿qué estrategia te das? ¿Qué aliados te buscás? ¿Qué situaciones reactivas te vas a encontrar? Buscando el menor grado de imprevisibilidad posible. (ex funcionario del ejecutivo provincial)

Hoy Tierra del Fuego está manejando -por lo menos los comentarios que existen- un presupuesto con casi un $80 \%$ en concepto de salarios. ¿Qué te queda para el resto? ¿Qué políticas públicas podés determinar a partir de eso salvo el endeudamiento? Lo están haciendo otras provincias ya. [...] Yo creo que si no sabemos quiénes somos y a dónde queremos ir, y si no estamos garantizados y estables para adentro, es muy complicado garantizarles a otros el desarrollo. (funcionario del ejecutivo provincial) 
En las tres citas precedentes encontramos ciertas continuidades: observar los actores que avalen o acompañen las decisiones, el diagnóstico de la situación presente y el objetivo futuro. Tres componentes necesarios para el desarrollo e implementación de políticas públicas. Sin embargo en ninguno de ellos se encuentra como ingrediente sustancial la información, y mucho menos la información estadística.

Otro punto importante para que se concretice un desarrollo local es el diseño independiente de políticas públicas. Para ello se debe gestionar e implementar información propia que permita evaluar el impacto de dichas políticas. En este sentido podemos observar que la provincia cuenta con un importante caudal de información estadística producto de sus acuerdos con organismos nacionales, principalmente el Instituto Nacional de Estadística y Censos (INDEC), pero tiene con muy poco desarrollo estadístico propio $^{6}$, esta característica evidencia la falta de sustento estadístico que la política local tiene en el diseño, monitoreo y evaluación.

\section{COMENTARIOS FINALES}

Al inicio del presente documento expusimos nuestro interés en indagar el marco de necesidad para un sistema de información estadístico que permita el monitoreo del desarrollo local sostenible. Hemos observado una serie definiciones que dejan en evidencia un concepto de desarrollo íntimamente vinculado a las dimensiones económica y social, en el que no se termina de concretar una visión multidimensional que incluya la dinámica ambiental e institucional. También apreciamos cierta omisión de la información en la elaboración de políticas públicas. En este sentido, quizá

\footnotetext{
6 Para dar un ejemplo el cálculo del Producto Bruto Provincial (PBP) no se actualiza desde 2007. Aunque se han realizado adecuaciones metodológicas en el Índice de Precios al Consumidor Provincial, y es probable que para el 2014 se cuente con un nuevo cálculo del PBP, dado que la Dirección General de Estadística y Censos de la provincia, junto al INDEC, se encuentran trabajando en el desarrollo del mismo. Entre los avances en materia estadística se puede citar la ampliación de la muestra en la Encuesta de Ocupación Hotelera y ciertas publicaciones de libre disponibilidad en su sitio de internet: http://estadisticas. tierradelfuego.gov.ar/
} 
sea necesario que se genere una nueva "cultura estadística" que visibilice a la información como un elemento importante para el diseño, monitoreo y evaluación de la política.

Por otra parte, las representaciones de los actores estatales de la política local nos permite observar cuáles son sus intereses a fin de explicar sus conductas (ACUÑA, 2013, p. 42). En nuestro caso lo que dicen los representa y construye cuál es su conceptualización acerca del desarrollo que pretenden.

Por momentos nuestros entrevistados se debaten entre si es o no una provincia desarrollada. Estas tensiones en la que entra el concepto se basan en contradicciones generadas en el seno del desarrollo local, ¿es exógeno o endógeno? La relación constante con la ley de promoción industrial lo deja en un espacio en el que entienden que el "desarrollo" fue alentado "desde afuera".

Responder si es una provincia desarrollada o no queda fuera del alcance del presente trabajo, quizá sea necesario un acercamiento a los indicadores lo que brinde ciertas perspectivas en ese sentido $^{7}$. Sin embargo la pregunta que surge se apoya en el debate generado en este documento ¿existe otra forma de desarrollo para la región? ¿Qué políticas públicas se generan para garantizar un desarrollo endógeno? La falta de relevancia y la baja producción de información estadística en el diseño, monitoreo e implementación puede ser un síntoma de la escasa producción de políticas elaboradas en este sentido. De esta forma arribamos a la formulación de una última pregunta: ¿Son las políticas públicas implementadas desde los estados locales de Tierra del Fuego las garantizan un desarrollo que se pueda independizar de la asistencia exógena?

7 Una aproximación en este sentido quizá de pueda encontrar en Hermida, M. (2013) ¿De que hablamos cuando hablamos de igualdad en Tierra del Fuego? en Sociedad Fueguina, Número 01, Año 01, Agosto de 2013, ICSE - UNTDF, Ushuaia. 


\section{REFERENCÍAS}

ACUÑA, C. ¿Cuanto importan las instituciones? Gobierno, estado y actores en la política argentina. Buenos Aires: Siglo XXI, 2013.

AGUADO, I.; BARRUTIA, J.; ECHEBARRIA, C. El desarrollo sostenible a lo largo de la historia del pensamiento económico. Revista de Economía Mundial, v. 21, p. 87-110, 2009.

AGUADO, I.; BARRUTIA, J.; ECHEBARRIA, C. Métricas para el desarrollo sostenible. En: JORNADAS DE ECONOMÍA CRÍTICA, 11., 27, 28 y 29 mar. 2008, Bilbao. Anales... Bilbao: UCM, 2008. Disponible en: <http://pendientedemigracion.ucm.es/info/ec/ ecocri/cas/aguado_xxx.pdf>. Consultado el: 24 ago. 2013.

AGUILERA, M. La importancia de indicadores armonizados para el desarrollo de políticas publicas. En: TALLER sobre la Medición de la Sociedad de la Información en América Latina y el Caribe. Río de Janeiro: Observatorio para la Sociedad de la Información en Latinoamérica y el Caribe (OSILAC), 2009.

AROCENA, F. El desarrollo sustentable: ¿oxímoron o solución? En: CONGRESS OF THE LATIN AMERICAN STUDIES ASSOCIATION, 11 al 14 jun. 2009, Rio de Janeiro. Anales... Rio de Janeiro: [s.n.], 2009.

CAMOU, A. Los consejeros del príncipe: saber técnico y política en los procesos de reforma económica en América Latina. Nueva Sociedad, Caracas, n. 152, p. 54-67, nov./dic. 1997.

CARDOSO, F. H.; FALETTO, E. Dependencia y desarrollo en América Latina. México, D.F.: Siglo Veintiuno, 1999.

CAVUOTO, N. L. "Herramientas para planificar el desarrollo: un Sistema de Información Territorial con enfoque de cadena de valor" Territorios, n. 20-21, pp. 176 enero/diciembre, 2009

FOLADORI, G.; TOMMASINO, H. El concepto de desarrollo sustentable treinta años después. Desenvolvimento e Meio Ambiente, Curitiba, n. 1, p. 41-56, jan./jun. 2000.

GALLOPÍN, G. Los indicadores de desarrollo sostenible: aspectos conceptuales y metodológicos. En: SEMINARIO DE EXPERTOS SOBRE INDICADORES DE SOSTENIBILIDAD EN LA FORMULACIÓN 
Y SEGUIMIENTO DE POLÍTICAS, 2006, Chile. Anales... Chile: [s.n.], 2006.

Sostenibilidad y desarrollo sostenible: un enfoque sistémico. Santiago de Chile: CEPAL, 2003.

HERMIDA, M. ¿De qué hablamos cuando hablamos de igualdad en Tierra del Fuego?. Sociedad Fueguina, Tierra del Fuego, Ushuaia, año 1, n. 1, 2013.

LUIZ., M. T.; SCHILLAT, M. La frontera austral, Tierra del Fuego, 1520-1920. Cadiz: Universidad de Cadiz, 1997.

MASTROSCELlO, M. La economía del fin del mundo; configuración, evolución y perspectivas económicas de Tierra del Fuego. Ushuaia: Cuatro Vientos, 2007.

NAÇÔES UNIDAS. Informe de la Comisión Mundial sobre el Medio Ambiente y el Desarrollo, "Nuestro futuro común". [S.l.]: United Nations, 1987. Disponible en: <http://www.un.org/es/comun/ docs/?symbol=A/42/427>. Consultado el: 15 ago. 2013

PICAZZO PALENCIA, E.; GUTIÉRREZ GARZA, E.; INFANTE BONFIGLIO, J.; CANTÚ MARTÍNEZ, P. La teoría del desarrollo humano y sustentable: hacia el reforzamiento de la salud como un derecho y libertad universal. Estudios Sociales, México, vol. 19, núm. 37, p. 254-279, ene./jun. 2011.

QUETGLAS, F. Qué es el desarrollo local: territorio, política y economía. Buenos Aires: Capital Intelectual, 2008.

REBORATTI, C. Ambiente y sociedad. Conceptos y relaciones. Buenos Aires: Planeta, 2000.

SEN, A. Teorías del desarrollo a principios del siglo XXI. Cuadernos de Economía, Bogotá, v. XVII, n. 29, 1998.

SVAMPA, M. La disputa por el desarrollo: territorio, movimientos de carácter socio-ambiental y discursos dominantes. [S.l.: s.n.], 2009. Disponible en: <http://www.maristellasvampa. net/archivos/ensayo43.pdf>. Consultado el: 24 ago. 2013.

VAN AERT, P. Hacia una comprensión y construcción genuina; el caso de la realidad social de Ushuaia. En: SEGUNDO CONGRESO DE ESTUDIANTES HISTORIA REGIONAL Y PATAGÓNICA, 2009, 
Ushuaia, Tierra del Fuego. Anales... Disponible en: <http://www. buenastareas.com/ensayos/Hacia-Una-Comprensi\%C3\%B3n-yConstrucci\%C3\%B3n-Genuina/252314.html>. Consultado el: 12 ago. 2013. 